\title{
A Study on the Psychological Characteristics of the Fluent State of the Skill Learning of the College Students
}

\author{
Ran Liu \\ College of Physical Education \\ Yan'an University \\ Yan'an, China 716000
}

\begin{abstract}
The training of special quality occupies a large proportion in the daily life of sports majors. How to improve students' training and learning effect and maintain or achieve better athletic performance is the main goal of physical education teaching in Colleges and universities. The state of fluency is a positive psychological experience. In such a state, people can devote themselves to their activities, concentrating their attention highly, moving smoothly and efficiently, and the whole process is an enjoyable experience. If it can induce the students to appear as much as possible in the skill learning, it will be of great help to the improvement of the teaching effect. In view of this, based on positive psychology and educational psychology theory, 200 college students majoring in physical education of Tianjin University of Sport, Wuhan Sports Institute, Shanghai Institute of Physical Education, Institute of Capital Institute of four sports colleges and universities as the research object, using the "trait flow scale -2, DFS-2" and "flow state scale -2, FSS-2 respectively to study" the skill in the psychological characteristics of flow state and trait fluency in learning. Study on different training period, sport grade, gender and special sports majors smooth psychological characteristics of single factor variance analysis, and in the course of the investigation according to the professional category stratified sample of 30 people to interview, to investigate the factors influencing college students majoring in physical education and its flow state controllability.
\end{abstract}

Keywords-physical education college students; fluent state; fluency; psychological characteristics

\section{INTRODUCTION}

According to the demand characteristics of sports professionals in China in the early twenty-first Century, it is an inevitable choice for sports majors to develop "general knowledge" sports talents with outstanding professional expertise in the discipline of sports discipline. In order to adapt to this situation, the physical education institutions adjust the proportion of the curriculum, which makes the basic theory courses greatly increased, and the special training hours are relatively reduced. At the same time, the enrollment expansion of college entrance examination has caused great changes in the quality of students' physical education, and the level of students' professional skills is uneven. Basic theory and special training should be "two hands to grasp, both hands must be hard". Since we have to compress special training hours, we can improve learning efficiency and effect only through limited teaching hours.

The state of fluency is the best psychological state. In this state, people can devote themselves to the activities they are engaged in, concentrating their attention highly, moving smoothly and efficiently, and the whole process itself is an enjoyable experience. If you can lure students as much as possible the flow state in practical learning, so to improve the effect of teaching is undoubtedly a great help. Although fluency is a psychological state that occurs in unconscious situations, some studies have confirmed that the factors that affect fluency are controllable. Therefore, we can take some measures to create conditions or remove obstacles for the emergence of fluency. Professional sports college students is a special group in Colleges and universities, although there are some similar training experience, but in the campus training and learning, this paper tries to research the athletic field flow state and combined with the characteristics of professional sports college students' psychological characteristics and its effect on fluency in skill learning state controllable investigation factors, provide practical suggestions to improve PE teaching quality, and to provide reference data for the study of flow state in the field of physical education.

\section{OBJECTS AND METHODS OF RESEARCH}

\section{A. Research Object}

The author selects the physical education and training professional and professional sports training to 200 college students from Tianjin University of Sport, Wuhan Sports Institute, Shanghai Institute of Physical Education, College of physical capital, the track and field 30, special Dragon Boat 40, 30 aerobics, sports dance special 40 basketball, 30 football, 30. There are 155 boys and 45 girls. The specific situation of the study sample is shown in "Table I". 


\begin{tabular}{|c|c|c|c|c|}
\hline \multirow[b]{2}{*}{ Special } & \multirow[b]{2}{*}{ Gender } & \multicolumn{3}{|c|}{ Level of motion } \\
\hline & & No movement grade $(n=74)$ & First-degree athletes $(n=20)$ & Second-grade athlete $(n=106)$ \\
\hline \multirow[t]{2}{*}{ track and field $(n=30)$} & Male & 0 & 0 & 24 \\
\hline & Female & 0 & 0 & 6 \\
\hline \multirow[t]{2}{*}{ Dragon Boat $(n=40)$} & Male & 3 & 12 & 25 \\
\hline & Female & 0 & 0 & 0 \\
\hline \multirow[t]{2}{*}{ Aerobics $(\mathrm{n}=30)$} & Male & 4 & 1 & 16 \\
\hline & Female & 1 & 5 & 3 \\
\hline Sports dance $(n=40)$ & Female & 29 & 2 & 9 \\
\hline \multirow[t]{2}{*}{ Basketball $(n=30)$} & Male & 19 & 0 & 11 \\
\hline & Female & 0 & 0 & 0 \\
\hline \multirow[t]{2}{*}{ Football $(n=30)$} & Male & 19 & 0 & 11 \\
\hline & Female & 0 & 0 & 0 \\
\hline
\end{tabular}

B. The Distribution and Recovery of the Questionnaire

230 questionnaires of "-2" were issued and 209 questionnaires were collected. The recovery rate was $90.8 \%$, and 10 of the invalid questionnaires were eliminated, and the effective recovery rate was $86.9 \%$. 230 questionnaires were issued for the "-2" questionnaire, 216 questionnaires were collected; the recovery rate was $93.9 \%$, and 16 invalid questionnaires were eliminated, and the effective recovery rate was $86.9 \%$.

\section{Research Methods}

1) Interview method: In this study, structured interviews were used to interview questions: (1) what are the factors that contribute to fluency experience in competition? (2) can fluency be controlled? (3) what factors can be controlled? What factors cannot be controlled?

2) Questionnaire: "flow state scale" -2 (FSS-2) contains 36 items questionnaire at the end of the flow state is used to evaluate the activity, is divided into nine subscales (each subscale had four items), nine dimensions respectively corresponding to the flow state: Challenge - skill the balance (Challenge-skills balance), action awareness merging (Action-awareness merging), clear goals (Clear goals) feedback, clear (Unambiguous feedback), to be absorbed in the current task (Total concentration on the task at hand (Sense of), control) a sense of control, loss of selfconsciousness (Loss of self-consciousness), time transform (Transformation of time) and enjoy the experience (Autotelic experience). The subjects of this scale should answer every statement (for example, I really enjoy that experience in the activity just now), according to Li Kete's 5 point scoring method, from "1" (totally disagree) to "5" (totally agree). The scale for evaluation activities, just completed so relevant data should be collected immediately after the end of the event, not later than one hour after the end of the event; more than one hour of data will be removed, so as to minimize interference on the subject, in order to avoid the influence to the measurement result. (The results of the validity test of the Chinese version of the scale are: $\mathrm{NNFI}=.905, \mathrm{CFI}=.917$, RMSEA $=.047$; the average reliability coefficient of each subscale is 0.74 .) Propensity measurement: trait mobility scale -2 (DFS-2) was used to evaluate the propensity of fluency experience, and its entries were the same as those in the fluency scale -2 (FSS-2), but changed in wording and tense. The scale of the scale is to evaluate the frequency of the subjects experiencing fluency characteristics in a given situation, that is, the general tendency. This scale requires subjects to recall that they used to experience the frequency of each fluent item (for example, I really enjoy this experience) in a specific activity before, and answered according to Li Kete's 5 point scoring method, from "1" (never) to "5" (always). This scale is an evaluation of fluency, so data should be collected for a period of time after the end of the game or the end of the event. (The results of the validity test of the Chinese version of the scale are: NNFI=.887, CFI $=.902$, RMSEA $=.051$; the average reliability coefficient of each subscale is 0.75 .)

\section{Data ANALYSIS ON FluENCY PSYChOlOGICAL CHARACTERISTICS OF PHYSICAL EDUCATION STUDENTS' SKILL LEARNING}

\section{A. The Influence of Training Years on the Fluency Status of College Students}

The students of physical education are divided into three categories according to different training years: under 3 years (including 3 years), 3 to 6 years, and more than 6 years. The single factor variance analysis was carried out on the scores of the students with different training years in the various dimensions of state fluency and idiosyncratic fluency. Multiple comparison and analysis were carried out on the indicators that showed significant differences in "Table II". 
TABLE II.

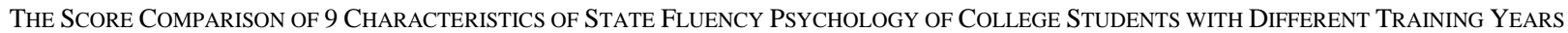

\begin{tabular}{|c|c|c|c|c|c|c|c|c|}
\hline & \multicolumn{2}{|c|}{ Under 3 years $(n=107)$} & \multicolumn{2}{|c|}{3 to 6 years $(n=59)$} & \multicolumn{3}{|c|}{ Over 6 years $(n=34)$} & \multirow[b]{2}{*}{$\mathbf{P}$} \\
\hline & $\mathbf{M}$ & SD & M & SD & M & SD & $\mathbf{F}$ & \\
\hline Challenge skills & 14.55 & 2.352 & 14.55 & 2.465 & 13.67 & 2.566 & 1.852 & .160 \\
\hline Awareness of action & 10.20 & 2.346 & 10.25 & 2.301 & 9.44 & 2.560 & 1.542 & .216 \\
\hline Clear target & 11.91 & 1.694 & 11.64 & 2.179 & 11.73 & 2.247 & .397 & .673 \\
\hline Clear feedback & 15.75 & 2.445 & 15.77 & 2.498 & 14.76 & 2.535 & 2.304 & .103 \\
\hline Focus & 15.21 & 2.794 & 14.89 & 3.009 & 14.55 & 2.894 & .734 & .481 \\
\hline Control & 10.71 & 1.763 & 10.96 & 2.042 & 10.61 & 2.335 & .436 & .647 \\
\hline Loss of consciousness & 11.83 & 2.489 & 13.01 & 3.753 & 11.50 & 2.351 & 4.128 & $.018^{*}$ \\
\hline Time transform & 13.66 & 2.598 & 13.98 & 3.031 & 12.79 & 3.796 & 1.779 & .171 \\
\hline Enjoy experience & 15.19 & 2.564 & 15.03 & 2.988 & 13.97 & 2.822 & 2.633 & .074 \\
\hline
\end{tabular}

a. Note: $* \mathrm{P}<0.05 * * \mathrm{P}<0.01$

TABLE III. The MUlTIPLE COMPARISON OF STUdENTS' STATUS FLUENCY IN THE LOSS OF CONSCIOUSNESS OF PHYSICAL EDUCATION STUDENTS WITH DIFFERENT TRAINING YEARS

\begin{tabular}{lllc}
\hline (I) training years & $(\mathbf{J})$ training years & \multicolumn{1}{c}{$\begin{array}{c}\text { Mean Difference } \\
(\mathbf{I}-\mathbf{J})\end{array}$} & sig \\
\hline Under 3 years & 3 to 6 years & -1.185 & $.013^{*}$ \\
3 to 6 years & Over 6 years & 1.516 & $.016^{*}$ \\
Over 6 years & Under 3 years & -.3317 & .562 \\
\hline \multicolumn{5}{r}{} & \multicolumn{2}{c}{${ }^{\text {b. }}$ Note: *P<0.05 ${ }^{* *} \mathrm{P}<0.01$}
\end{tabular}

The "Table III" shows that there is a significant difference in the loss of self-awareness among the college students with different training years. On this index, the students who had trained for 3 to 6 years scored the highest, and had significant differences with those of the other two groups, but there was no significant difference between the students who had trained for a period of three years or less than those who had trained for six years or more. From the overall score, students who had trained for more than 6 years scored lower than those with a clearer goal than those below 3 years (3 years) or 3 to 6 years.

TABLE IV.

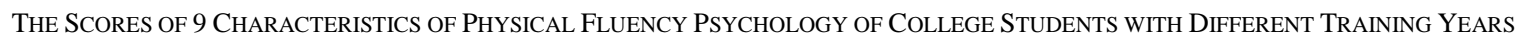

\begin{tabular}{|c|c|c|c|c|c|c|c|c|}
\hline & \multicolumn{2}{|c|}{ Under 3 years $(n=107)$} & \multicolumn{2}{|c|}{3 to 6 years $(n=59)$} & \multicolumn{2}{|c|}{ Over 6 years $(n=34)$} & \multirow[b]{2}{*}{$\mathbf{F}$} & \multirow[b]{2}{*}{$\mathbf{P}$} \\
\hline & $\mathbf{M}$ & SD & $\mathbf{M}$ & SD & $\mathbf{M}$ & SD & & \\
\hline Challenge skills & 13.71 & 2.739 & 13.98 & 2.374 & 13.23 & 1.985 & .949 & .389 \\
\hline Awareness of action & 9.78 & 2.331 & 9.76 & 2.028 & 8.88 & 2.358 & 2.231 & .110 \\
\hline Clear target & 11.31 & 1.959 & 11.01 & 2.549 & 11.55 & 2.077 & .729 & .484 \\
\hline Clear feedback & 15.28 & 2.705 & 14.35 & 3.252 & 14.50 & 2.364 & 2.445 & .089 \\
\hline Focus & 14.71 & 2.860 & 14.15 & 3.402 & 13.41 & 3.105 & 2.480 & .086 \\
\hline Control & 10.33 & 2.082 & 10.66 & 1.834 & 10.08 & 2.301 & .918 & .401 \\
\hline Loss of consciousness & 11.34 & 2.761 & 11.49 & 2.207 & 10.38 & 2.558 & 2.253 & .108 \\
\hline Time transform & 13.09 & 2.504 & 13.06 & 2.958 & 12.55 & 2.401 & .565 & .569 \\
\hline Enjoy experience & 15.22 & 2.685 & 14.38 & 4.004 & 13.94 & 2.448 & 2.808 & .063 \\
\hline
\end{tabular}

The results of "Table IV" show that there is no significant difference in the dimensions of the quality of physical education among the college students with different training years. From the score point of view, students who have trained for more than 6 years have scored lower than those with less than 3 years (including 3 years) or 3 to 6 years in addition to clear goals and precise feedback. The cause of more than 6 years of training students fluent and smooth state trait had poorer scores may be learning content of these students did not change much in the professional training of almost lifelong lack of freshness, learning enthusiasm is not high, and the longest duration of training the student movement level is relatively high, and the school in order to meet the needs of all students usually choose moderate or lower the difficulty of the learning task, makes this kind of students "challenge" and "skill" is not balanced, the flow is difficult to be reflected. However, the results of fluency and fluency showed that the fluency of college students in physical education has nothing to do with the length of training.

\section{B. The Influence of Sports Grade on the Fluency} Psychology of College Students in Physical Education

According to the sports grade of college students, the subjects are divided into first class level, two level movement levels, and no sports grade. A single factor ANOVA was used to analyze the differences in 9 characteristics of State Sports fluency, psychology and trait fluency among college students majoring in sports technology. 
TABLE V.

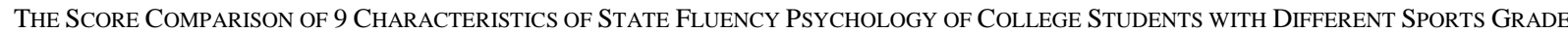

\begin{tabular}{|c|c|c|c|c|c|c|c|c|}
\hline & \multicolumn{2}{|c|}{ No motion grade $(n=74)$} & \multicolumn{2}{|c|}{ level $1(n=20)$} & \multicolumn{2}{|c|}{ level $2(n=106)$} & \multirow[b]{2}{*}{$\mathbf{F}$} & \multirow[b]{2}{*}{$\mathbf{P}$} \\
\hline & $\mathbf{M}$ & SD & M & SD & $\mathbf{M}$ & SD & & \\
\hline Challenge skills & 14.05 & 2.262 & 15.05 & 2.416 & 14.52 & 2.534 & 1.618 & .201 \\
\hline Awareness of action & 9.94 & 2.099 & 10.30 & 2.577 & 10.15 & 2.532 & .247 & .781 \\
\hline Clear target & 11.63 & 1.716 & 12.75 & 1.585 & 11.74 & 2.106 & 2.753 & .066 \\
\hline Clear feedback & 15.45 & 2.450 & 16.30 & 2.515 & 15.55 & 2.518 & .921 & .400 \\
\hline Focus & 14.71 & 2.645 & 16.45 & 2.964 & 14.94 & 2.953 & 2.987 & .053 \\
\hline Control & 10.44 & 1.895 & 11.95 & 2.038 & 10.78 & 1.897 & 4.880 & $.009 * *$ \\
\hline $\begin{array}{ll}\text { Loss } & \text { of } \\
\text { consciousness } & \end{array}$ & 12.12 & 2.749 & 12.20 & 2.706 & 12.11 & 3.139 & .007 & .993 \\
\hline Time transform & 13.16 & 2.460 & 14.10 & 3.552 & 13.83 & 3.160 & 1.410 & .247 \\
\hline Enjoy experience & 14.66 & 2.858 & 15.05 & 2.892 & 15.11 & 2.677 & .597 & .552 \\
\hline
\end{tabular}

TABLE VI. The Multiple COMPARison of StATE of CONTROL of STATE OF FLUENCY IN PHYSICAL EDUCATION STUDENTS WITH DIFFERENT SPORTS GRADES

\begin{tabular}{llll}
\hline (I) level of motion & \multicolumn{1}{c}{$\begin{array}{c}(\mathbf{J}) \text { level of } \\
\text { motion }\end{array}$} & \multicolumn{1}{c}{$\begin{array}{c}\text { Mean Difference } \\
(\mathbf{I}-\mathbf{J})\end{array}$} & sig \\
\hline No motion grade & level 1 & -1.504 & $.002^{* *}$ \\
level 1 & level 2 & 1.166 & $.013^{*}$ \\
level 2 & No motion grade & .3370 & .246 \\
\hline & & \multicolumn{2}{c}{ e. Note: *P<0.05 ** $\mathrm{P}<0.01$}
\end{tabular}

The "Table V" and "Table VI" show different sport grade students of professional sports psychological state flow in the sense of control there is a significant difference between the indicators, there are significant differences between the specific performance of non-sports level of students with a grade level of sports students, a grade level of sports students and two sports level students had significant difference, but not significant two level the level of sports students and nonsports grade differences of students.

A player's score in this index is slightly lower than the two level of pleasant experience athletes in other index scores were higher than two athletes and sports level of students, two athletes in each index scores were higher than non-sports grade students.

TABLE VII. DIFFERENCES IN 9 CHARACTERISTICS OF TRAIT FluENCY PSYCHOLOGY OF COLLEGE STUDENTS WITH DifFERENT SPORTS GRADES

\begin{tabular}{|c|c|c|c|c|c|c|c|c|}
\hline & \multicolumn{2}{|c|}{ No motion grade(n=74) } & \multicolumn{2}{|c|}{ level $1 \quad(n=20)$} & \multicolumn{2}{|c|}{ level 2（n=106) } & \multirow[b]{2}{*}{$\mathbf{F}$} & \multirow[b]{2}{*}{$\mathbf{P}$} \\
\hline & $\mathbf{M}$ & SD & M & SD & $\mathbf{M}$ & SD & & \\
\hline Challenge skills & 13.14 & 2.541 & 13.80 & 2.284 & 14.09 & 2.497 & 3.145 & $.045^{*}$ \\
\hline Awareness of action & 9.18 & 1.848 & 9.90 & 2.314 & 9.87 & 2.483 & 2.201 & .113 \\
\hline Clear target & 11.17 & 1.925 & 11.70 & 1.922 & 11.25 & 2.366 & .465 & .629 \\
\hline Clear feedback & 14.85 & 2.768 & 15.00 & 2.714 & 14.87 & 2.949 & .021 & .979 \\
\hline Focus & 14.33 & 3.119 & 14.65 & 2.254 & 14.26 & 3.228 & .130 & .878 \\
\hline Control & 10.05 & 1.999 & 11.40 & 1.313 & 10.43 & 2.147 & 3.527 & $.031 *$ \\
\hline Loss of consciousness & 11.17 & 2.360 & 12.00 & 2.752 & 11.11 & 2.712 & 1.006 & .368 \\
\hline Time transform & 12.89 & 2.458 & 12.95 & 3.316 & 13.07 & 2.617 & .109 & .897 \\
\hline Enjoy experience & 14.78 & 3.364 & 14.20 & 2.3753 & 14.84 & 3.094 & .363 & .696 \\
\hline
\end{tabular}

TABle VIII. The Multiple Comparison of the Trait Fluency Psychology of College Students With DifFerent Sports Grades

\begin{tabular}{lllll}
\hline & (I) level of motion & (J) level of motion & Mean Difference(I-J) & sig \\
\hline Challenge skill & No motion grade & level 1 & -.6513 & .301 \\
& level 1 & level 2 & -.2943 & .629 \\
& level 2 & No motion grade & .9456 & $.013^{*}$ \\
\hline Sense of control & No motion grade & level 1 & -1.345 & $.009^{* *}$ \\
& level 1 & level 2 & .9660 & .052 \\
& level 2 & No motion grade & .3799 & .217 \\
\hline
\end{tabular}

g. Note: *P<0.05 **P<0.01

The results of the "Table VII" and "Table VIII" show that there are significant differences in the characteristics of fluency Psychology among sports majors with different sports grades: two indicators of challenge skill balance and control sense. There was significant difference between the students with no movement grade and the two level sports level in the challenge skill balance index. There was a significant difference in the control sense index between the students with first grade sports level and those of the first level sports level. There was no significant difference between the first level sports level and the two level sports level student. From the score to see a player in addition to challenge skills, time transformation, enjoyable experience of the three outside index scores were higher than two athletes and sports level of students, two athletes in addition to focus on the current task and loss of consciousness beyond the scores were higher than those in the non-sports level of students. This indicates that the higher the sport level is, the more confident it is to their sports skills. In terms of skill mastery, they have higher perception of their sports ability, 
emotional stability, emotional control ability and psychological self-control ability. and idiosyncratic fluency psychology of college students of different sex.

\section{Comparison of Fluency Psychological Characteristics of College Students of Different Sex:}

A single factor analysis of variance was carried out on the psychological characteristics of state fluency psychology

TABLE IX. SCORES On 9 Indicators of State Fluency of ColLEge Students With DifFerent SeX

\begin{tabular}{|c|c|c|c|c|c|c|}
\hline & \multicolumn{2}{|c|}{$\operatorname{Male}(n=155)$} & \multicolumn{2}{|c|}{ Female $(n=45$} & \multirow[b]{2}{*}{$\mathbf{F}$} & \multirow[b]{2}{*}{$\mathbf{P}$} \\
\hline & $\mathbf{M}$ & SD & $\mathbf{M}$ & SD & & \\
\hline Challenge skills & 14.74 & 2.403 & 13.24 & 2.186 & 14.07 & $.000 * *$ \\
\hline Awareness of action & 10.23 & 2.470 & 9.57 & 1.959 & 2.720 & .101 \\
\hline Clear target & 11.80 & 1.970 & 11.80 & 1.853 & .000 & .984 \\
\hline Clear feedback & 15.80 & 2.530 & 14.86 & 2.232 & 5.059 & $.026 *$ \\
\hline Focus & 15.17 & 2.828 & 14.44 & 2.981 & 2.265 & .134 \\
\hline Control & 11.03 & 1.879 & 9.86 & 1.925 & 13.41 & $.000 * *$ \\
\hline Loss of consciousness & 12.25 & 3.055 & 11.66 & 2.504 & 1.409 & .237 \\
\hline Time transform & 13.57 & 3.095 & 13.73 & 2.517 & .100 & .753 \\
\hline Enjoy experience & 15.06 & 2.722 & 14.51 & 2.881 & 1.404 & .238 \\
\hline
\end{tabular}

TABle X. Score of Trait Fluency Psychology of College Students of Different SEX IN 9 IndeXes

\begin{tabular}{|c|c|c|c|c|c|c|}
\hline & \multicolumn{2}{|c|}{ Male $(n=155)$} & \multicolumn{2}{|c|}{ Female $(n=45$} & \multirow[b]{2}{*}{$\mathbf{F}$} & \multirow[b]{2}{*}{$\mathbf{P}$} \\
\hline & M & SD & $\mathbf{M}$ & SD & & \\
\hline Challenge skills & 14.10 & 2.420 & 12.37 & 2.424 & 17.70 & $.000^{* *}$ \\
\hline Awareness of action & 9.72 & 2.374 & 9.26 & 1.814 & 1.457 & .229 \\
\hline Clear target & 11.28 & 2.191 & 11.22 & 2.098 & .028 & .867 \\
\hline Clear feedback & 14.91 & 2.973 & 14.75 & 2.385 & .110 & .740 \\
\hline Focus & 14.45 & 3.135 & 13.91 & 2.937 & 1.065 & .303 \\
\hline Control & 10.64 & 1.982 & 9.51 & 2.062 & 11.20 & $.001 * *$ \\
\hline Loss of consciousness & 11.28 & 2.532 & 11.02 & 2.808 & .354 & .552 \\
\hline Time transform & 12.86 & 2.665 & 13.44 & 2.454 & 1.709 & .193 \\
\hline Enjoy experience & 14.93 & 3.088 & 14.15 & 3.218 & 2.182 & .141 \\
\hline
\end{tabular}

"Table IX" and "Table X" shows the different gender subjects in challenge skills balance, sense of control, clear feedback three indicators showed significant difference, and male subjects in each index score on the psychological state of fluid in addition to "time shift" outside were higher than those of female subjects.

The result of "Table IX" shows that the gender fluency of different gender subjects is significantly different from those of the two indicators of challenge skill balance and high control sense, and the scores of male subjects on all indexes are higher than those of female subjects except for "time transformation".

It shows that male subjects experience more fluency than women in the classroom. Generally speaking, men are more aware of their sports ability than women, and they are more interested in sports. They are more concerned about training or competition, and are more easily excited, and have more confidence in motor skills, so that they can get more fluent experience.

\section{Comparison of Fluency Psychological Characteristics of College Students with Different Specialties:}

According to item group theory, students of different majors can be divided into physical fitness class (track and field dragon boat), skill performance class (aerobics and sports dance) and skill confrontation class (basketball and football). A single factor ANOVA was used to analyze the differences of state fluency and idiosyncratic fluency in three different subjects. The results of "Table XI" show that different special students show significant differences in 8 indicators except for "loss of consciousness". The students with special physical skills in challenge skills balance, action awareness merging, clear feedback, focus on the current task, sense of control and time transformation 6 indexes had significant difference, and the confrontation in the skills challenge skills balance, clear goals, focus, sense of control, when before task time transform and enjoy the experience of the 6 indexes have significant difference, skill performance and special skills against students only in clear goals and enjoy the experience index show significant difference.

Physical fitness students' state fluency and psychological scores in these eight indicators are all higher than those of skill performance class and skill antagonism class, indicating that physical fitness students in the classroom experience more fluency than other two groups of students. This may be due to the fact that physical fitness teachers often use the competition method in the teaching process, such as dragon boat training, often divide the players into two groups to compete, so as to improve their enthusiasm. The creation of the competition situation can greatly improve the students' enthusiasm for learning, is a good way to induce fluency. 
TABLE XI. SCORE COMPARISON OF 9 CHARACTERISTIC INDEXES OF STATE FluENCY PSYCHOLOGY FOR DifFERENT SPORTS MAJORS

\begin{tabular}{|c|c|c|c|c|c|c|c|c|}
\hline & \multicolumn{2}{|c|}{ Physical type $(n=70)$} & \multicolumn{2}{|c|}{ Skill expression class $(n=70)$} & \multicolumn{2}{|c|}{ Skill versus class $(n=60)$} & \multirow[b]{2}{*}{$\mathbf{F}$} & \multirow[b]{2}{*}{$\mathbf{P}$} \\
\hline & M & SD & M & SD & $\mathbf{M}$ & SD & & \\
\hline Challenge skills & 15.15 & 2.453 & 14.05 & 2.388 & 13.93 & 2.283 & 5.417 & $.005 * *$ \\
\hline Awareness of action & 10.68 & 1.974 & 9.48 & 2.369 & 10.10 & 2.659 & 4.623 & $.011 *$ \\
\hline Clear target & 12.38 & 1.386 & 11.85 & 1.898 & 11.06 & 2.298 & 8.033 & $.000 * *$ \\
\hline Clear feedback & 16.18 & 1.746 & 15.20 & 2.494 & 15.36 & 3.075 & 3.164 & $.044 *$ \\
\hline Focus & 15.77 & 2.341 & 14.77 & 2.761 & 14.40 & 3.370 & 4.183 & $.017 *$ \\
\hline Control & 11.34 & 1.760 & 10.52 & 2.026 & 10.40 & 1.941 & 4.826 & $.009 * *$ \\
\hline Loss of consciousness & 12.20 & 2.624 & 11.84 & 2.624 & 12.36 & 3.603 & .543 & .582 \\
\hline Time transform & 14.78 & 2.105 & 13.67 & 2.837 & 12.16 & 3.375 & 14.26 & $.000 * *$ \\
\hline Enjoy experience & 15.42 & 2.109 & 15.14 & 2.950 & 14.13 & 3.055 & 3.959 & $.021 *$ \\
\hline
\end{tabular}

TABLE XiI. The Multiple Comparison of State Fluency Psychology of College Students in Different SPeCialties

\begin{tabular}{lllll}
\hline & \multicolumn{1}{c}{ (I) special } & \multicolumn{1}{c}{ (J) special } & Mean Difference(I-J) & sig \\
\hline Challenge skills & Physical type & Skill expression & 1.100 & $.007 * *$ \\
& Skill expression & Skill versus class & .1238 & .768 \\
& Skill versus class & Physical type & -1.223 & $.004 * *$ \\
\hline Awareness of action & Physical type & Skill expression & 1.200 & $.003 * *$ \\
& Skill expression & Skill versus class & -.6142 & .136 \\
& Skill versus class & Physical type & -.5857 & .155 \\
\hline Clear target & Physical type & Skill expression & .5285 & .097 \\
& Skill expression & Skill versus class & .7904 & $.018 *$ \\
& Skill versus class & Physical type & -1.319 & $.000 * *$ \\
\hline Clear feedback & Physical type & Skill expression & .9857 & $.019 *$ \\
& Skill expression & Skill versus class & -.1666 & .701 \\
& Skill versus class & Physical type & -.8190 & .060 \\
\hline Focus & Physical type & Skill expression & 1.000 & $.038 *$ \\
& Skill expression & Skill versus class & .3714 & .456 \\
& Skill versus class & Physical type & -1.371 & $.006 * *$ \\
\hline Control & Physical type & Skill expression & .8142 & $.013 *$ \\
& Skill expression & Skill versus class & .1285 & .703 \\
& Skill versus class & Physical type & -.9428 & $.006 * *$ \\
\hline Time transform & Physical type & Skill expression & 1.114 & $.019 *$ \\
& Skill expression & Skill versus class & 1.504 & .002 \\
& Skill versus class & Physical type & -2.619 & $.000 * *$ \\
\hline Enjoy experience & Physical type & Skill expression & .2857 & .535 \\
& Skill expression & Skill versus class & 1.009 & $.036 *$ \\
& Skill versus class & Physical type & -1.295 & $.007 * *$ \\
\hline
\end{tabular}

The results in "Table XII" showed that the psychological characteristics of different majors showed significant difference in 4 indicators: challenge skill balance, clear goal, and control sense and time transformation. Students with special skills of physical performance of special students in the sense of control index significantly, and the categories of special skills against students' differences in the 4 indicators are very significant; skill performance and special skills against students only in the clear target showed significant difference.

The students in the class of special physical challenge skills balance, action awareness merging, accurate feedback, attention to the current task and control these five indicators of the highest score, the students in the class of special skill performance goals, loss of consciousness, time transformation and enjoy the experience of these four indicators of the highest score, this that trait fluent psychology has its professional characteristics. Special skills against students scored lowest, may be due to different teaching methods and the special impact on the learning effect, the teachers often use special physical fitness class competition method in the teaching process, the creation of the game situation can promote the smooth state; special skill performance of the students are learning and training in the accompaniment of music studies have shown that the flow will appear more frequently in the work situation of music, so the physical stamina and skill performance categories of special students than special skills against students are more likely to experience a sense of fluency. 
TABLE XIII. DIFFERENCES IN THE 9 CHARACTERISTICS OF IDIOSYNCRATIC FLUENCY PSYCHOLOGY OF COLLEGE STUDENTS WITH DiFFERENT SPECIALTIES

\begin{tabular}{|c|c|c|c|c|c|c|c|c|}
\hline & \multicolumn{2}{|c|}{ Physical type $(n=70)$} & \multicolumn{2}{|c|}{ Skill expression class $(n=70)$} & \multicolumn{2}{|c|}{ Skill versus class $(n=60)$} & \multirow[b]{2}{*}{$\mathbf{F}$} & \multirow[b]{2}{*}{$\mathbf{P}$} \\
\hline & $\dot{M}$ & SD & $\mathbf{M}$ & SD & M & SD & & \\
\hline Challenge skills & 14.38 & 2.600 & 13.51 & 2.471 & 13.16 & 2.344 & 4.253 & $.016^{*}$ \\
\hline Awareness of action & 9.97 & 2.160 & 9.55 & 2.137 & 9.30 & 2.499 & 1.475 & .231 \\
\hline Clear target & 11.47 & 1.742 & 11.67 & 1.931 & 10.56 & 2.676 & 4.850 & $.009 * *$ \\
\hline Clear feedback & 15.05 & 2.339 & 14.77 & 2.599 & 14.80 & 3.602 & .208 & .812 \\
\hline Focus & 14.62 & 2.450 & 14.51 & 2.701 & 13.76 & 4.031 & 1.452 & .237 \\
\hline Control & 11.00 & 1.857 & 10.11 & 2.109 & 10.00 & 2.066 & 5.004 & $.008 * *$ \\
\hline Loss of consciousness & 11.40 & 2.410 & 11.50 & 3.034 & 10.70 & 2.165 & 1.799 & .168 \\
\hline Time transform & 13.21 & 2.289 & 13.37 & 2.813 & 12.30 & 2.669 & 3.133 & $.046^{*}$ \\
\hline Enjoy experience & 14.78 & 2.489 & 15.18 & 2.935 & 14.23 & 3.894 & 1.509 & .224 \\
\hline
\end{tabular}

TABLE XIV. The Multiple Comparison of IDIOSYNCRATIC Fluency PSychology of COLLEGe Students In DifFERENT SPECIALTIES

\begin{tabular}{lllll}
\hline & \multicolumn{1}{c}{$(\mathbf{I})$ special } & \multicolumn{1}{c}{$(\mathbf{J})$ special } & Mean Difference (I-J) & sig \\
\hline Challenge skills & Physical type & Skill expression & .8714 & .039 \\
& Skill expression & Skill versus class & .34762 & .427 \\
& Skill versus class & Physical type & -1.219 & $.006^{* *}$ \\
\hline Clear target & Physical type & Skill expression & -.2000 & .578 \\
& Skill expression & Skill versus class & 1.104 & $.004^{*}$ \\
& Skill versus class & Physical type & -.9047 & $.016^{*}$ \\
\hline Control & Physical type & Skill expression & .8857 & $.010^{*}$ \\
& Skill expression & Skill versus class & .1142 & .747 \\
& Skill versus class & Physical type & -1.000 & $.005^{* *}$ \\
\hline Time transform & Physical type & Skill expression & -.1571 & .721 \\
& Skill expression & Skill versus class & 1.071 & .020 \\
& Skill versus class & Physical type & -.9142 & $.047^{*}$ \\
\hline
\end{tabular}

\section{CONCLUSION AND SUGGESTION}

\section{A. Conclusion}

- Sports college students with different training years showed significant difference in state fluency only in self-consciousness loss index, but there was no significant difference in trait fluency.

- Different sports level of professional sports college psychological state flow in the sense of control indicators have significant differences, and score index in addition to the pleasant experience slightly lower than the two level athletes athletes, in other index scores were higher than two athletes and sports level of students, and two athletes the scores were higher than those in the non-sports level of students. There are significant differences in the two indicators that challenge a skill balance and a sense of control. And the level of athletes in addition to challenge skill and time transformation, enjoyable experience of the three outside index scores were higher than two athletes and sports level of students, two athletes in addition to focus on the current task and loss of consciousness beyond the scores were higher than those in the non-sports level of students.

- Gender fluency of subjects showed significant difference in three indicators: challenge skill balance, high control sense and clear feedback, and male subjects scored higher than those of female subjects in different indicators of state fluency. There are significant differences in the trait fluency of different gender subjects in the two indicators of challenge skill balance and high control sense, and the scores of male subjects on all indexes are higher than those of female subjects except for "time transformation".

- In addition to the "loss of consciousness" on the 8 indicators of different professional sports students showed significant difference in the state of flow. The scores of the students in the physical class group major are all higher than those of the skill group and the skill antagonism group in the eight indexes.

\section{B. Suggestion}

1) Self-regulation: Suitable for body dimension importance is ranked in the first place, participants cited rate reached $75 \%$, good health is undoubtedly the prerequisite technology play, through interviews with $63 \%$ of the students believe that the flow state is in conscious state, can be achieved through their own efforts, establish a regular schedule, good habits, reasonable diet collocation, make oneself can have a good health.

To cultivate self-confidence and positive attitude, in the process of learning to correctly evaluate themselves, learn to appreciate themselves, experience the joy of success. Undeniable sports ability are individual differences, to make the movement of students with lower level clear, do not put their sports ability look too heavy, let them know, doing sports is not only to win the gold medal of honor or, in the study of the one point one drops of progress in training is also appreciated. For those students with a high level of 
industry should not to guard against arrogance and rashness, than their low ability students with big with pride in their daily learning, still should not ignore practical training, basic training, and establish a more ambitious goal.

2) To play the leading role of teachers: Although the impact of teachers on the fluency of sports majors is not the most important factor in interviews, more than half of the students believe that the role of teachers is an important factor.

Teachers play a leading role in the teaching process, and the quality of teachers' own quality directly affects the students' learning effect. First, as a sports professional teacher, professional skills must be excellent, so that students can have an intuitive example in training and learning. Only when students are recognized by themselves can students get the recognition of this course. In the course of teaching, we should pay attention to the teaching of different levels according to the actual situation of the students. According to the actual situation of the students, the proportion of men and women, the level of sports, the students are divided into flexible and diverse groups, so as to teach students in accordance with their aptitude. In the hierarchical teaching, for some students based teaching can be carried out by the normal procedure, and those on the basis of poor students to properly arrange some demonstration and explanation, so that they can have a correct and objective understanding of professional learning, and enhance their participation and learning confidence. To alleviate the psychological burden, create a relaxed and harmonious atmosphere of teaching. We should consider comprehensively the training contents and training methods. We should not only let the poor students grasp, but also let the high level students feel bored. Therefore, physical education teachers should continue to explore ideas and actively research new teaching methods, such as incentive, praise, situational, discovery, heuristics, trial, cooperation, competition and so on, and explore diversified teaching methods. For the teaching of physical education students, the proper use of competition method and the creation of competition situation in the classroom can achieve better teaching results.

Teaching and extracurricular guidance to encourage and praise the students, academic success is a catalyst to stimulate learning motivation in the teaching process should be targeted for students to give a positive evaluation and feedback to students through language, facial expressions, and body and so on, in order to increase the confidence of students. Pay attention to the small progress of the students in the process of learning or training, and give a timely affirmation, more observation and deep excavation of the students' glittering points. For students with poor grades, help them find out the reasons, put forward specific requirements, encourage them to treat setbacks and failures correctly, inspire them to see their own progress, so as to get rid of the trouble of learning "vicious circle" and increase the intensity of learning motivation.

3) To improve the teaching environment: Of occupation moral education of skilled teachers, strengthen the responsibility of the teachers, sports teachers' behavior norms. Encourage skilled teachers go out training, engage in research activities, so as to update the concept of teachers and teaching methods.

The construction of sports venues and gymnasiums can meet the standards of the regulations of the national colleges and universities, and meet the practical needs of professional teaching and students' technical skills. Reform the school sports venues management system, give full play to the functions of all venues, and do not let any stadiums and venues idle. In addition to the normal school time, all the schools will be open to students at any time to meet the needs of learning after school.

The motivation of physical education college students is greatly influenced by the social environment and family, and the education of sports colleges and universities should coordinate with the society and family education. The effect of each student's learning is also influenced by the consciousness of the group, so we should attach importance to the formation of good.

We should improve the atmosphere of school and class, in order to promote the students' learning motivation to the correct direction.

\section{REFERENCES}

[1] Liu micro. Psychological characteristics of fluency in sports and cognitive intervention [D]. East China Normal University doctoral thesis, 2009:2-60.

[2] Liang Bin. A survey on the characteristics and psychological factors of fluency psychology of football players and their psychological factors; [D]. Wuhan Sports Institute master's degree thesis, 2004.

[3] Hu Yongmei, Zhang Jian, Liu Songbo, et al. Main characteristics of fluency and mental state of baseball and softball players. Journal of Tianjin University of Sport, 2002, (1): 17-29..

[4] Zhang Zhongqiu. The best psychological state of Chinese athletes skills competitions and the individual state of psychological research on the influencing factors of [C]. 2002 Hanyin seventh national sports psychology Symposium collection.

[5] Hu Yongmei, Sun Aihua, Sun Yanlin, Ji Chengshu. Skill showing category of athletes flow state induced factors and controllable [J] Journal of Tianjin University of Sport, 2004, 19 (1): 27-30. [40]

[6] Sun Yanlin. A study on the state of fluency psychology of athletes [J]. Journal of Tianjin University of Sport, 2000, (3): 12-15. 